\title{
Longitudinal Assessment of the Association Between the Use of Sexually Explicit Material, Hyperfemininity, and Sexual Agency in Adolescent Women
}

Klein, Verena; Šević, Sandra; Kohut, Taylor; Štulhofer, Aleksandar

Source / Izvornik: Psychology \& Sexuality, 2020

Journal article, Accepted version

Rad u časopisu, Završna verzija rukopisa prihvaćena za objavljivanje (postprint)

https://doi.org/10.1080/19419899.2020.1757500

Permanent link / Trajna poveznica: https://urn.nsk.hr/urn:nbn:hr:131:911493

Rights / Prava: In copyright/Zaštićeno autorskim pravom.

Download date / Datum preuzimanja: 2023-04-26

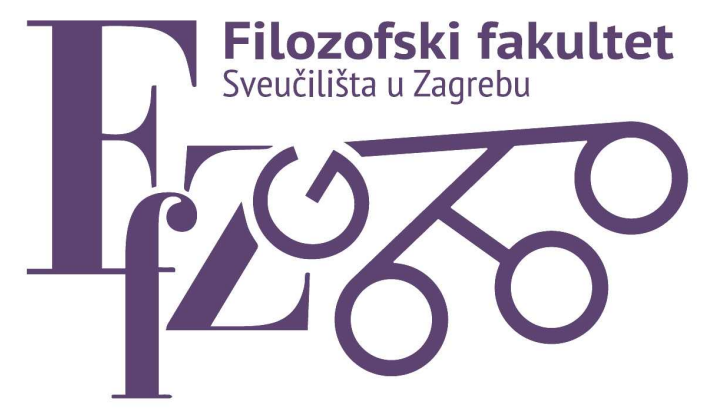

Repository / Repozitorij:

ODRAZ - open repository of the University of Zagreb Faculty of Humanities and Social Sciences
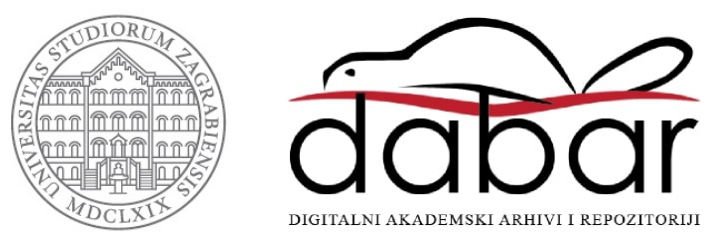
Longitudinal Assessment of the Association Between the Use of Sexually Expli Material, Hyperfemininity, and Sexual Agency in Adolescent Women

\title{
Verena Klein $^{1}$, Sandra Šević ${ }^{2}$, Taylor Kohut ${ }^{3}$, and Aleksandar Štulhofer ${ }^{2}$
}

${ }^{1}$ Institute for Sex Research and Forensic Psychiatry, University Medical Center HamburgEppendorf, Hamburg, Germany

${ }^{2}$ Department of Sociology, Faculty of Humanities and Social Sciences, University of Zagreb, Croatia

${ }^{3}$ Department of Psychology, University of Western Ontario, London, Canada

\begin{abstract}
Author Note
Verena Klein, Institute for Sex Research and Forensic Psychiatry, University Medical Center Hamburg-Eppendorf, Martinistraße 52, 20246 Hamburg, Germany; Sandra Šević, and Aleksandar Štulhofer, Department of Sociology, Faculty of Humanities and Social Sciences, University of Zagreb, Ivana Lucica 3, 10000 Zagreb, Croatia; Taylor Kohut, Department of Psychology, University of Western Ontario, London, Canada
\end{abstract}

Corresponding author: Verena Klein, Email: vklein@uke.de, fax: +49-40-7410-56406 phone: $+49-40-7410-57622$ 


\begin{abstract}
There is growing public concern that sexually explicit material (SEM) negatively affects women, given that, more often than not, SEM promotes women's sexual objectification, passivity and submission to male desire. Focusing on hyperfemininity and sexual agency, as possible respectively negative and positive outcomes of SEM use, using a sample of 552 female high school students $\left(M_{\text {age }}\right.$ at baseline $\left.=15.8, S D=.48\right)$ who participated in a 5 -wave longitudinal study in Croatia, we first assessed if and to what extent are hyperfemininity and sexual agency related to adolescent women's sexual wellbeing, examining the cross-sectional relationships between these two constructs and sexual satisfaction. We then assessed longitudinal associations between SEM use and hyperfemininity/sexual agency over a period of 24 months. The results of the cross-sectional analysis indicated that sexual satisfaction was positively associated with sexual agency, but not with hyperfemininity, although at only one point in time. The results of directed latent growth modelling indicated that while baseline levels of SEM use were significantly and positively associated with both sexual agency and hyperfemininity two years later, an increase in SEM use over time was significantly, albeit weakly, related only to hyperfemininity. Given the possibility that SEM use may contribute to the development of hyperfemininity in adolescent women, the findings of this study call for further investments into comprehensive sexual education programs for youth that include discussions about SEM.
\end{abstract}

Key Words: Sexually explicit material; Sexual agency; Hyperfemininity; Sexual Satisfaction; Adolescent women; Longitudinal design 
SEM, HYPERFEMININITY, AND SEXUAL AGENCY

Longitudinal Assessment of the Association Between the Use of Sexually Explicit Material, Hyperfemininity, and Sexual Agency in Adolescent Women

The growing availability and ease of access to sexually explicit material (SEM) ${ }^{1}$ has prompted an increased scholarly interest in the effects of SEM on healthy adolescent development (Koletić, 2017). Although they may use SEM less often than boys and men (Peter \& Valkenburg, 2016), SEM could be particularly harmful for girls and women. Antipornography feminists have long emphasized that mainstream SEM more often than not promotes and encourages the sexual objectification of women (Attwood, 2004; Smith \& Attwood, 2014). Although reductive, this reasoning is not without evidence, since in most of the mainstream SEM women's bodies are used as objects that aid in the achievement of male sexual gratification and dominance and women are portrayed as passive and submissive to male desire (Bridges, Wosnitzer, Scharrer, Sun, \& Liberman, 2010; Gorman, Monk-Turner, \& Fish, 2010; Klaassen \& Peter, 2015). If internalized, sexually objectified representations of women in SEM could manifest as hyperfemininity. Therefore, on the one hand, exposure to SEM may result in women both desiring to please men with little regard for their own pleasure and starting to perceive themselves primarily through their physical appeal, thus adopting an objectified view of their bodies and themselves (Fredrickson \& Roberts, 1997). On the other hand, through the use of SEM, women could learn about their sexuality and further explore their sexual preferences (Ashton, McDonald, \& Kirkman, 2018), and viewing SEM itself may be an active and empowered sexual choice. This way, rather than internalizing an objectified view of themselves, through the use of SEM women may develop sexual agency and experience a greater sense of control over their own bodies and sexual life.

\footnotetext{
${ }^{1}$ SEM encompasses pictures or videos that depict explicit sexual activities (e.g., masturbation, oral sex, vaginal and anal penetration) with an intent to sexually arouse the viewer (see Valkenburg \& Peter, 2016).
} 
SEM, HYPERFEMININITY, AND SEXUAL AGENCY

Considering that adolescence is an important developmental period during which both gender roles become more salient and, beginning to explore their sexuality, adolescents start to form patterns of sexual behaviour that may persist well into adulthood (de Graaf \& Rademakers, 2006), there is surprisingly little empirical research on SEM use among young women, although several studies have shown that SEM use may affect offline sexual behavior among young women (Maas, Bray, \& Noll, 2019; Maas \& Dewey, 2018). The current study, therefore, extends the previous literature in several ways. First, aiming to assess if and to what extent are hyperfemininity and sexual agency related to adolescent women's sexual wellbeing, this study explores the cross-sectional relationship between hyperfemininity/sexual agency and sexual satisfaction. Secondly, we assess the change in the use of SEM among women over a period of 24 months during the transition from middle to late adolescence. Finally, in order to explore both the negative and the positive effects of SEM use on adolescent women's development, this study assesses the longitudinal relationship between SEM use and respectively hyperfemininity and sexual agency.

\section{Hyperfemininity and SEM Use among Adolescents}

An adherence to a stereotypical feminine gender role and sexual beliefs, in the literature referred to as hyperfemininity, encompasses three interrelated dimensions that include using sexuality and physical attributes to appeal to men, the fundamental importance of having a relationship with a man, and the preference for men who also conform to a traditional male gender role, such as being dominant and in control (Kreiger \& Dumka, 2006; Murnen \& Byrne, 1991, van Oosten et al., 2015). SEM, particularly when it depicts an objectifying sexual script and a traditional gender dynamic, i.e. a submissive woman and dominant men, could therefore engender or over time strengthen a hyperfeminine orientation in young women. 
SEM, HYPERFEMININITY, AND SEXUAL AGENCY

Within the framework of the objectification theory (Fredrickson \& Roberts, 1997), exposure to sexually objectifying portrayals of women may over time both trigger sexual objectification of others and, if internalized, it may also lead to self-objectification or viewing oneself through the observer's eyes. In the context of SEM use, exposure to media content that objectifies women and treats the female body as a tool used by men puts women at risk of internalizing objectifying social messages communicating that a woman's value is expressed through physical appearance, sexual appeal, and the ability to attract men. Furthermore, mainstream SEM most often also portrays a stereotypical gender dynamic, with women taking on a passive and men a dominant role (Bridges et al., 2010; Gorman et al., 2010; Klaassen \& Peter, 2015). Over time, such gender schemas (Bem, 1981) may be integrated into a woman's self-concept, leading her to enact corresponding behaviour. For example, if young women are repeatedly exposed to sexually objectifying images of women in SEM, they may start to evaluate their worth primarily through their beauty and appeal to men and thus exhibit a higher degree of hyperfemininity. In other words, SEM may predict greater endorsement of hyperfeminity, in part due to the internalization of the sexual objectification of women. Previous research has linked hyperfemininity with a greater acceptance of the objectification of women, and women higher in hyperfemininity tend to view themselves as sexual objects rather than as sexual subject (Murnen \& Byrne, 1991), which puts them at risk of manifesting self-objectifying behaviours, such as body surveillance (Liss, Erchull, \& Ramsey, 2011). Importantly, however, the relationship between SEM use and hyperfemininity is likely bidirectional. Correlational and experimental research conducted in adult populations has suggested that women high in hyperfemininity use sexually objectifying media more frequently and tend to be less critical of men's dominant and sexually coercive behaviour, which is often featured in SEM (McKelvie \& Gold, 1994; van Oosten, Peter, \& Boot, 2015). Longitudinal studies conducted in adolescent populations 
SEM, HYPERFEMININITY, AND SEXUAL AGENCY

reported a relationship between hyperfeminity and sexy online self-presentation, exposure to violent SEM content, and the likelihood of initiating watching SEM (Vandenbosch, 2015; Vandenbosch \& Peter, 2016).

Several other studies explored the relationship between adolescents' gender and sexual attitudes and SEM use. For example, there is cross-sectional and longitudinal evidence that SEM use is positively associated with viewing women as sexual objects (Peter \& Valkenburg, 2007, 2009; Vandenbosch \& van Oosten, 2017), less progressive gender role attitudes in general (Brown \& L'Engle, 2009), and the acceptance of stereotyped gender roles and power imbalance in sexual relationships (To, Ngai, \& Iu Kan, 2012). However, one other longitudinal study found no association between SEM use and a belief that women engage in token resistance to sex (Peter \& Valkenburg, 2011).

\section{Sexual Agency: Could Women Benefit from SEM?}

Pro-pornography feminists have emphasized that women should be seen as more than passive victims of pornography (e.g., Abrams, 1995). If sexual representations of women are always seen negatively, it is easy to overlook the possibility that young women can be sexual subjects who enjoy sexual self-expression and physical intimacy. Moreover, overemphasizing the negative consequences of sexualization may further marginalize women's sexual pleasure, self-expression, and agency (e.g., Lerum \& Dworkin, 2009; Peterson, 2010).

Sexual agency is the ability to express sexual desires and preferences, to communicate sexual expectations and boundaries, and to feel entitled to receiving and giving sexual pleasure (Anderson, 2013; Kiefer \& Sanchez, 2007). Although sexual agency has been conceptualized in various ways, the construct typically refers to the ability to act according to one's own wishes, being sexually assertive, and having control over one's own sexual life (for a review, see Fahs \& McClelland, 2016; p. 396). Being high in sexual agency, similarly, 
SEM, HYPERFEMININITY, AND SEXUAL AGENCY

means taking on an active and empowered role in a sexual encounter and being able to express what one wants and does not want to do sexually (Ramsey \& Hoyt, 2015).

Viewing SEM may strengthen sexual agency in women. More so than another source of sexual pleasure, SEM might also provide young women with content for exploration and development of their own sexual preferences. This indeed is supported by previous research among adult women (for a review, see Ashton et al., 2018). Not only do women report positive affective experiences with SEM use (Chadwick, Raisanen, Goldey, \& van Anders, 2018; Goodson, McCormick, \& Evans, 2001; Parvez, 2006; Weinberg, Williams, Kleiner, \& Irizarry, 2010), such as increased sexual arousal and more sexual fantasizing (Parvez, 2006; Paul \& Shim, 2008), but SEM also provides them with opportunities to learn about sexuality and sexual behaviours (e.g., sexual likes and dislikes), their own sexual arousal patterns, and it helps them to communicate their sexual needs to their partners (Hare, Gahagan, Jackson, \& Steenbeek, 2014, 2015). Given that (sexual) behaviors can be learned by observing and imitating others, SEM use may increase sexual agency by providing young women with examples of behavior which they consider worth imitating (e.g., cognitive social learning theory, see Petersen \& Hyde, 2011).

\section{Sexual Agency, Hyperfeminity and Sexual Satisfaction}

Research suggests that sexual agency and hyperfeminity are associated with sexualityrelated outcomes also outside of SEM use. For example, sexual agency could increase feelings of sexual satisfaction by enhancing one's autonomy during sexual activities (Kiefer \& Sanchez, 2007), given that sexual agency fosters communication of sexual desires and wishes and feelings of entitlement to receive sexual pleasure. And indeed, previous research suggested that sexual agency is positively related to sexual wellbeing and satisfaction among both adult and adolescent women (Horne \& Zimmer-Gembeck, 2006; Kiefer \& Sanchez, 
SEM, HYPERFEMININITY, AND SEXUAL AGENCY

2007; Klein, Becker, \& Štulhofer, 2018; Sanchez, Kiefer, \& Ybarra, 2006; Zimmer-Gembeck \& French, 2016).

Hyperfeminity, however, is likely negatively related to sexual satisfaction, as it is positively associated with both the internalization of the sexual objectification of women and with the instrumental use of sexuality. For example, cross-sectional research conducted among girls and young women found that the internalization of traditional gender ideologies is negatively associated with, respectively, sexual agency and body esteem during sex (e.g., Curtin, Ward, Merriwether, \& Caruthers, 2011; Impett, Schooler, \& Tolman, 2006). Furthermore, women high in hyperfeminity tend to use sexuality as a means to attract men or maintain a relationship. Such extrinsic rather than intrinsic treatment of sexuality as well as the possible prioritization of their partner's pleasure may negatively affect young women's ability to communicate their sexual needs and desires and therefore lower their sexual satisfaction.

\section{Study Aims}

Drawing on previous research, we first explored the cross-sectional association between hyperfemininity/sexual agency and sexual satisfaction. Although we did expect that sexual agency and sexual satisfaction will be positively associated (Horne \& Zimmer Gembeck, 2006; Kiefer \& Sanchez, 2007; Sanchez, Kiefer, \& Ybarra, 2006; Zimmer Gembeck \& French, 2016), the relationship between hyperfemininity and sexual satisfaction has yet not been assessed in research literature. However, considering that women's sexual health and wellbeing are negatively associated with traditional femininity ideologies (e.g., Curtin et al., 2011; Impett et al., 2006) and rather than intrinsic, hyperfeminity represents an extrinsic treatment of sexuality and prioritization of the partner's needs in a sexual encounter, hyperfemininity is likely to be negatively associated with sexual satisfaction. 
SEM, HYPERFEMININITY, AND SEXUAL AGENCY

Using data collected over a period of 24 months, we then explored the changes in SEM use among women during the transition from middle to late adolescence. It has been shown, prospectively, that some female adolescents increase their use of SEM during this developmental period (Doorwaard, van den Eijden, Overbeeck, \& ter Bogt, 2014; Štulhofer, Tafro, \& Kohut, 2019). Finally, aiming to explore both the negative and the positive effects of SEM use on adolescent women's development, we assessed the longitudinal relationship between SEM use and respectively hyperfemininity and sexual agency. In other words, we assessed whether sexual agency and hyperfemininity at the age of 18 are significantly predicted by participants' pornography use at the age of 16 (i.e., in the previous developmental period), as well as if they are predicted by subsequent growth in pornography use. Comparing the two estimates allows us to answer the following question: Are female sexual agency and hyperfemininity in late adolescence influenced more by pornography use in middle adolescence or by changes in use between middle and late adolescence? Given that adolescence is a period during which gender roles become more salient (Curtin et al., 2011), changes, and in particular an increase in SEM use may potentially contribute to the development of hyperfemininity in young women. Since this is also a time when most women have their first romantic and sexual experiences, use of SEM might also affect young women's sexual knowledge and ability to communicate their sexual needs, thus contributing to the development of sexual agency.

\section{Method}

\section{Participants}

The panel sample of adolescents used in this study was recruited from 14 larger secondary schools in Rijeka, the third largest city in Croatia. ${ }^{2}$ The baseline survey $(\mathrm{T} 1, n=$

\footnotetext{
${ }^{2}$ Fourteen of the total of 22 high-schools in the Rijeka metropolitan area were selected for participation. Smaller schools $(n=7)$ were omitted due to financial constraints; one larger school was not included due to a recent arson. Coverage of the city's high-school sophomore population was calculated to be at $63 \%$.
} 
SEM, HYPERFEMININITY, AND SEXUAL AGENCY

1,291) took place in December 2015 among students who were high-school sophomores at the time. Four more data collection waves were carried out (T2, $n=1,283$; T3, $n=1,233$; T4, $n=1,117$ and $\mathrm{T} 5, \mathrm{n}=931^{3}$ ) at approximately 6-month intervals.

In this study, we used responses from 552 female students $\left(M_{\text {age }}\right.$ at baseline $=15.8$, $\mathrm{SD}=.48$ ) who participated in the final wave (T5), when sexual agency and hyperfemininity were measured, and in at least one other wave. To address attrition bias, multivariate binary logistic regression analysis was used to compare women who participated in the final wave to those who did not. Independent variables included in the model were type of school (vocational schools vs. more prestigious gymnasiums), academic achievement, father's and mother's education, religiosity and the frequency of SEM use at baseline. The sole difference between the two groups was their academic achievement. Compared to other participants, students who were included in this study reported a higher academic achievement $(\mathrm{AOR}=$ $1.49, p<.01)$.

\section{Procedure}

Classroom-based self-administered paper and pencil surveying was used for data collection. To ensure confidentiality, large portable screens were placed between participants. Information needed for informed consent was delivered by trained field assistants and was also included on the first page of the questionnaire. Because Croatian guidelines for ethical research in children and adolescents stipulate that adolescents older than 14 years can give consent, students' parents were sent a leaflet with basic information about our longitudinal study prior to baseline data collection but no consent was sought from them. Contact information for a youth psychological health center was provided at the end of each

\footnotetext{
${ }^{3}$ The difference in the sample size at T5 was related to the fact that students enrolled in 3-year vocational programs completed their studies before the start of fieldwork for T5.
} 
SEM, HYPERFEMININITY, AND SEXUAL AGENCY

questionnaire. All study procedures were approved by the Ethical Research Committee of the Faculty of Humanities and Social Sciences at the University of X.

\section{Measures}

Frequency of SEM use in the period of 6 months preceding the survey was assessed at all five waves (T1-T5) using a single-item indicator. Answers were anchored on an 8-point response scale ranging from $1=$ never to $8=$ several times a day. In the questionnaire itself, SEM was defined as any material which openly (i.e., not censored) depicts sexual activity. Material which shows naked bodies, but not sexual intercourse or other sexual activity does not belong to pornography as here defined. Stability coefficients for SEM use were in the $.57-.77$ range $(p<.01)$.

Sexual agency, Hyperfemininity, and Sexual satisfaction were measured only at T5. Sexual agency was measured using the 3-item Self-efficacy in Achieving Sexual Pleasure subscale of the Female Sexual Subjectivity Inventory (e.g., If I were to have sex with someone, I'd show my partner what I want and I would not hesitate to ask for what I want sexually from a romantic partner) (Horne \& Zimmer-Gembeck, 2006). To anchor answers, we used a 5-point scale ranging from $1=$ it does not relate to me at all to $5=$ it relates to me completely. The brief scale had satisfactory reliability in this study (Cronbach's $\alpha=.89$ ).

Hyperfemininity was assessed using the adapted 6-item version (see van Oosten et al., 2015) of the Hyperfemininity Scale (Murnen \& Byrne, 1991). The original 26-item scale, using a forced choice format included three domains: (a) the importance of being in a relationship with a man; (b) the use of sex to gain or maintain a romantic relationship; and (c) the preference for traditional male behaviour in partners (see van Oosten et al., 2015; Murnen \& Byrne, 1991). Given that previous research pointed to psychometric difficulties with the first dimension, the adapted short version of the Hyperfemininity Scale encompassed the two latter dimensions (items include Sometimes women need to make men feel jealous, so they 
SEM, HYPERFEMININITY, AND SEXUAL AGENCY

will be more appreciative and I would agree to have sex with a man if I thought I could get

him to do what I want). Since we were interested in a dimensional assessment of

hyperfemininity, we also adapted the response format. Instead of answering dichotomously, study participants recorded their responses on a 5-point scale ranging from $1=$ it does not relate to me at all to $5=$ it relates to me completely. The scale had acceptable internal consistency (Cronbach's $\alpha=.76$ ), identical to the one reported in the original study (Murnen \& Byrne, 1991).

Sociodemographic controls were father's and mother's education (ranging from $1=$ less than primary school to $5=$ a university degree), and religiosity, operationalized by the frequency of attending religious services (responses ranged from $1=$ never to $6=$ once a week or more often).

\section{Analytical Strategy}

Hierarchical linear regression modelling with multiple imputation $(k=20)$ of missing information was used to comparatively assess time invariant correlates of sexual agency and hyperfemininity. First, two unconditional means models were tested in order to address intraclass correlation related to cluster-based sampling (participants were nested in high school classes). Full models, with grand mean centered independent variables (mother's and father's education, personal religiosity, and sexual satisfaction) were tested in the next step. Restricted maximum likelihood (REML) estimation method was used at both steps.

Latent growth curve modelling (LGM) was used to explore the association between change in SEM use over time and adolescent women's sexual agency and hyperfemininity at T5. This approach allows for the estimation of group changes over time (fixed effects), as well as individual differences in growth trajectories (random effects). When growth is linear, it is represented by two factors-a latent intercept and a latent slope. Their means represent the average value at baseline and the average growth (positive or negative) over time, 
SEM, HYPERFEMININITY, AND SEXUAL AGENCY

respectively, while their variances reflect individual variability in initial levels and growth rates (Little, 2013; Preacher, Wichman, MacCallum, \& Briggs, 2008). Compared to traditional approaches to longitudinal data analysis, LGM has several advantages including assessment of within-individual change and the related associations, higher statistical power (Muthén \& Curran, 1997), unproblematic handling of missing data and unequally spaced time points, as well as somewhat higher robustness to non-normally distributed measures (Curran, Obeidat, \& Losardo, 2010; Duncan, Duncan, \& Strycker, 2013; Muthén \& Curran, 1997).

The LGM procedure involved several steps. First, linear and quadratic growth curves in SEM use were fitted, with time represented in months (due to uneven spacing of the study waves). Because the linear growth model $\left(\chi^{2}(13)=44.64\right)$ fitted the data substantially worse than the quadratic model $\left(\chi_{(9)}^{2}=14.52\right)$, a piecewise growth curve was specified to facilitate interpretation (Flora, 2008). Based on descriptive information ${ }^{4}$ (i.e., mean use over time) about the change in SEM use, the five waves were divided into two linear growth periods: A (T1-T3) and B (T4-T5). Significant latent growth characterized the first, but not the second period. The fit of piecewise linear model $(\mathrm{AIC}=41.15)$ and the quadratic model $(\mathrm{AIC}=$ 36.52) were similar.

Following the exploration of latent curves, a directed unconditional model was fitted to the data. Three latent factors representing piecewise growth in SEM use were specified as predictors of sexual agency and hyperfemininty. Both dependent variables were operationalized as latent constructs, with one difference: in the case of hyperfemininity, observed variables were included as 2-item parcels. Next, the directed model was trimmed for parsimony by omitting nonsignificant paths (nonsignificant $\Delta \chi^{2}$ test comparing the full

\footnotetext{
${ }^{4}$ This is a usual procedure when searching for "a knot", or a time-point in which the (overall) latent curve can be split in two (for the so called piecewise curve specification). A well-chosen knot is a point that separates two distinct parts of the latent curve. Based on the observation of changes in mean frequency of pornography use in our panel, we identified the knot that separated the first part of the curve, characterized by a significant increase in pornography use, from the second part, in which no increase was observed. The procedure is described in more detail in Flora (2008) and Grimm, Ramm, \& Estabrook (2017).
} 
SEM, HYPERFEMININITY, AND SEXUAL AGENCY

and trimmed models indicated that the omission was acceptable). Following standard guidelines (Byrne, 2010; Little, 2013), $\chi^{2} / \mathrm{df}$ ratio $\leq 2$, comparative fit index (CFI) values $\geq$ .95 and root mean square error of approximation (RMSEA) values $\leq .05$ (with the upper $90 \%$ confidence interval value $\leq .08$ ) indicated excellent fit to the data. Based on the inspection of missing information patterns, which pointed to reasonably small deviations from random missingness (MAR), full information maximum likelihood (FIML) estimation was employed in LGM (Graham, 2012).

\section{Results}

At baseline, over two thirds of participants (69.2\%) did not use SEM. Use of SEM once a week or more frequently was reported by about every tenth female adolescent in the sample (9.7\%). During the observed period, SEM use was not very common. By T5, as many as $41.1 \%$ of adolescent women in our sample have never used SEM and those who have, have done so once a month or less frequently. Cross-correlations among the constructs of interest are shown in Table 1. Predictably, hyperfemininity was negatively $(r=-.14, p<.01)$ and sexual agency was positively related $(r=.34, p<.01)$ to sexual satisfaction. Overall, SEM use was significantly and positively associated with sexual agency and, although not as consistently, with hyperfemininity. The effect sizes, however, were small.

\section{TABLE 1 ABOUT HERE}

\section{Comparative Assessment of the Correlates of Sexual Agency and Hyperfemininity}

Before exploring the correlates of adolescents' sexual agency and hyperfemininity, unconditional means models were tested to address the relationship between classroom environment and the outcome variables. In both cases, the percentage of variance in the outcome explained by classroom-level nesting was marginal (2.7\%). Nonetheless, full hierarchical regression models were tested, and the results are presented in Table 2. According to the findings, sexual satisfaction was strongly and significantly related only to 
SEM, HYPERFEMININITY, AND SEXUAL AGENCY

sexual agency $(b=0.55, p=.000)$. The association with hyperfemininity was negative but did not reach statistical significance. Of the sociodemographic controls included in the models, only baseline religiosity was significantly and negatively associated with sexual agency scores two years later $(b=-0.25$, S.E. $=.04, p<.003)$.

\section{TABLE 2 ABOUT HERE}

\section{Adolescent Women's SEM Use Over Time and Sexual Agency/Hyperfemininity}

The piecewise latent growth model of SEM use in adolescent women fitted the data well $\left(\chi^{2}(9)=19.15, \mathrm{CFI}=.99, \mathrm{RMSEA}=.045[90 \% \mathrm{CI}=.016-.073]\right)$. The latent intercept and slope A (T1-T3) values were statistically different from zero $(M=1.78$, S.E. $=.06, p<$ .001 and $M=.06$, S.E. $=.02, p<.01$, respectively). Apart from this average growth in SEM use in the period between $\mathrm{T} 1$ and T4, we also observed statistically significant within-person variation in both baseline levels of (var. $=1.41, p<.001)$ and slope A latent change in SEM use $($ var. $=.09, p<.001)$. The latent slope B $($ T4-T5) failed to reach significance $(M=-.06$, S.E. $=.05, p>.22$; var. $=.06, p>.45)$, suggesting that the average within-person increase in SEM use ended at approximately 17 years of age and then stabilized or marginally decreased.

To address whether the change over time in SEM use predicted sexual agency and hyperfemininity scores, a directed model was tested next. The model was characterized by good fit: $\chi^{2}(42)=87.95, \mathrm{CFI}=.98, \mathrm{RMSEA}=.045(90 \% \mathrm{CI}=.031-.058)$. The final, trimmed, model $\left(\chi^{2}(44)=91.40, \mathrm{CFI}=.98, \mathrm{RMSEA}=.044[90 \% \mathrm{CI}=.031-.057]\right) \mathrm{was}$ obtained by omitting all paths from the insignificant latent slope B (see Figure 1).

Whereas initial levels of SEM use were significantly associated with both sexual agency and hyperfemininity $(\beta=.23$, S.E. $=.03, p<.001$ and $\beta=.18$, S.E. $=.04, p<.01$, respectively), so that participants with a higher frequency of SEM use at baseline reported higher sexual agency and hyperfemininity scores, positive growth in SEM use over time was significantly related to hyperfemininity $(\beta=.17$, S.E. $=.21, p<.05)$ but not sexual agency. It 
SEM, HYPERFEMININITY, AND SEXUAL AGENCY

should also be noted that the two outcomes were weakly correlated $(r=.15$, S.E. $=.04, p<$ $.01)$. Female adolescents' pornography use during the observed period accounted for $5 \%$ of variance in sexual agency and $6 \%$ of variance in hyperfemininity.

\section{FIGURE 1 ABOUT HERE}

\section{Discussion}

Expanding previous literature on young women's sexuality, we first sought to assess the cross-sectional relationship between sexual satisfaction and respectively hyperfemininity and sexual agency in adolescent women. Focusing on SEM use, we then explored the change in the use of SEM among women over a period of 24 months during the transition from middle to late adolescence. Finally, in order to explore both the negative and the positive effects of SEM use on adolescent women's development, we assessed the longitudinal relationship between SEM use and respectively hyperfemininity and sexual agency. Although there is increasing concern that sexually objectifying content in SEM may harm girls and women (Koletić, 2017), there is also evidence suggesting SEM use can have certain potential benefits for women's sexual wellbeing, such as greater sexual knowledge and better communication about sexuality (e.g., Goodson et al., 2001; Parvez, 2006; Weinberg et al., 2010).

Complementing previous research suggesting that sexual agency is positively related to (young) women's sexual wellbeing (Horne \& Zimmer-Gembeck, 2006; Kiefer \& Sanchez, 2007; Sanchez, Kiefer, \& Ybarra, 2006; Zimmer-Gembeck \& French, 2016), sexual agency was in our study strongly and positively associated with sexual satisfaction. Although further efforts aimed at promoting sexual agency among adolescent and young women are needed, it is important to keep in mind that women's sexual agency is not easy to achieve given that the socio-cultural environment that provides the context for sexual development is characterized by a sexual double standard (Kreager, Staff, Gauthier, Lefkowitz, \& Feinberg, 2016; Lyons, 
SEM, HYPERFEMININITY, AND SEXUAL AGENCY

Giordano, Manning, \& Longmore, 2011; Young, Cardenas, Donnelly, \& Kittleson, 2016). Specifically, in a society that tends to support "male sexual values" (e.g., the importance of intercourse), young men continue to have more freedom in expressing themselves sexually, whereas young women receive mixed messages about sexuality and face more barriers when they wish to assert their sexual desires and needs (Fine \& McClelland, 2006; Tolman, 2005).

Whereas hyperfemininity and sexual satisfaction were weakly but significantly negatively associated at the bivariate level, we failed to observe a significant association between hyperfemininity and sexual satisfaction after controlling for the effects of parental education and religiosity in the multivariate analysis. Although this finding doesn't indicate that hyperfemininity is detrimental to young women's achievement of sexual satisfaction, it also doesn't suggest that it is beneficial. Previous research, however, suggests that rather than empowering, self-sexualization and instrumental use of sexuality are better seen as performative (i.e., acceptance or popularity seeking) and partner-focused-resulting in little regard for one's own pleasure (e.g., Ward, Seabrook, Grower, Giaccardi, \& Lippman, 2018). Considering the previously reported association between hyperfemininity and anxiety, body surveillance and body shame (Liss et al., 2011; Nowatzki \& Morry, 2009), all of which are negatively associated with sexual satisfaction (e.g., Calogero \& Thompson, 2009; Claudat \& Warren, 2014), our results call for future studies focusing on hypergender orientation and its implications for young women's sexual well-being, preferably over time.

We then explored the changes in SEM use among women during the transition from middle to late adolescence. While at baseline two thirds of our study participants had never used SEM, by the end of the observed period, this was true for about $40 \%$ of adolescent women included our sample. Although a recent review article reported that prevalence rates vary greatly across studies (Peter \& Valkenburg, 2016), at $58.9 \%$ by the end of the observed period, the prevalence of SEM use reported in our study seems to be at the higher end. In 
SEM, HYPERFEMININITY, AND SEXUAL AGENCY

part, however, this is due to the fact that our sample included somewhat older adolescent women. Of note is also that SEM use was not very common in our sample; adolescent women who did use SEM on average did so only once a month or less frequently.

Finally, we assessed the longitudinal relationship between SEM use and respectively hyperfemininity and sexual agency. Given that adolescence is a time when both gender roles become more salient (Curtin et al., 2011; Impett et al., 2006) and most girls and women begin to have their first romantic and sexual experiences, we aimed to explore the potential negative and positive effects of SEM use on adolescent development. Our results suggested that the initial frequency of SEM use (at the age of 16) was significantly and positively related to both sexual agency and hyperfemininity two years later, while the increase in SEM use over time was positively, albeit weakly, associated only with hyperfemininity. Our results, therefore, tentatively support previous evidence suggesting that both the use and an increase in the use of sexually objectifying content over time is associated with the adoption of objectifying gender and sexual scripts and self-objectifying thoughts and behaviours, which are characteristic of hyperfemininity (e.g., Karsay et al., 2018; Ward, 2016; Zurbriggen et al., 2010). Keeping in mind that hyperfemininity was in this study measured only at the end of the observed period, this finding may be due to SEM use strengthening the hyperfeminine gender orientation in adolescent women or it could be that women who have a stronger hyperfeminine orientation experience greater increases in SEM use over time. Although it is likely that the relationship between SEM use and hyperfemininity is bidirectional and mutually enforcing, future research would benefit from assessing to what extent is SEM use implicated in the development of hyperfemininity and, alternatively, to what extent does a hyperfeminine gender orientation motivate increasing engagement with SEM during adolescence. Currently, only one longitudinal study so far has reported that hyperfeminity increased the likelihood of initiating watching SEM among adolescent girls 
SEM, HYPERFEMININITY, AND SEXUAL AGENCY

(Vandenbosch \& Peter, 2016). Lastly, although the baseline level of SEM use was positively associated with sexual agency two years later, an increase in SEM use over time was not

related to sexual agency in this study, suggesting that an increase in SEM use over time likely does not result in greater sexual agency. Importantly, however, as it was the case with hyperfemininity, it is likely that the relationship between SEM use and sexual agency is bidirectional. Whereas viewing SEM may increase sexual agency in women, choosing to use SEM can also be seen as an expression of sexual agency in women and an active sexual choice, one that comes from a desire to take responsibility for one's own sexuality and pleasure.

\section{Implications}

Given that SEM use may contribute to the development of hyperfemininity in adolescent women, the findings of this study call for strengthening of media literacy and comprehensive sexual education programs for young people (Rothman et al., 2018). Pornography literacy education aims to increase awareness about unrealistic and gender stereotypical representations of sexual interaction and gender dynamics enacted in SEM (Albury, 2014; Vandenbosch \& van Oosten, 2017). Even though much work remains to be done in this field (Albury, 2014; Haste, 2013), several recently published studies provide some evidence that pornography literacy interventions can contribute to a decrease in the sexual objectification of women (Rothman et al., 2018; Vandenbosch \& van Oosten, 2017). The results of the present study suggest that young women, in particular those who have a stronger hyperfemine gender orientation, could benefit from comprehensive sexual education programs that include media literacy education and discussions that may help them both to deconstruct biases and distorted gender relations that are often portrayed in SEM and to develop skills necessary for the communication of sexual expectations and boundaries (Rothman et al., 2018; Vandenbosch \& van Oosten, 2017). 
SEM, HYPERFEMININITY, AND SEXUAL AGENCY

\section{Study Strengths and Limitations}

This appears to be the first study to explore the relationship between hyperfemininity and sexual satisfaction among adolescent women and to provide a longitudinal assessment of the role of SEM use in female adolescents' sexual agency and hyperfemininity. Another strength of this study is the use of a statistical approach that allowed a robust analysis of between-individual differences in SEM use based on within-individual latent trajectories of use during the transition from middle to late adolescence.

An important limitation of our study is that hyperfemininity, sexual agency, and sexual satisfaction were measured only in the final study wave. Therefore, we assessed the relationship between sexual satisfaction and hyperfemininity/sexual agency only crosssectionally, in the final study wave, which prevents causal interpretations of the findings. In other words, it may be that higher sexual agency leads to greater sexual satisfaction as well as that greater sexual satisfaction leads to higher sexual agency. Similarly, although we did not observe a significant relationship between sexual satisfaction and hyperfemininity in the final wave of our study, it is possible that they are related over time. Given that we measured hyperfemininity and sexual agency only in the final study wave, we were also not able to account for baseline levels of sexual agency and hyperfemininity in the longitudinal analysis. Controlling for the baseline levels of sexual agency and hyperfemininity would likely attenuate the observed association between the change in SEM use over time and hyperfemininity, although estimation biases linked to autoregressive components should also be taken into account when considering this limitation (see Wilkins, 2018).

Finally, we did not assess SEM content and therefore were not able to explore the relationships between different SEM genres and hyperfemininity/sexual agency. Although it is likely that women in our study viewed mainstream SEM, which is primarily targeted at men (Johansson \& Hammarén, 2007; Wallmyr \& Welin, 2006) and most often portrays 
SEM, HYPERFEMININITY, AND SEXUAL AGENCY

sexual scripts that may lead to the internalization of sexual objectification (Fritz \& Paul, 2017), it may be interesting and consequential to move beyond the general approach to the study of women`s experience with SEM (i.e., investigating whether pornography use in general is good or bad for women). Future research would benefit from exploring if and how exposure to for example feminist pornography and content that centres women's pleasure affect the development of hyperfemininity/sexual agency in adolescent and young women.

\section{Conclusions}

Aiming to longitudinally assess the relationship between SEM use, hyperfemininity, and sexual agency, this study found that although the initial levels of SEM use were related to both hyperfeminity and sexual agency two years later, an increase in SEM use over time was significantly, albeit weakly, related only to hyperfemininity. Given that adolescence is an important developmental period during which gender roles become more salient and most girls and young women begin to have their first romantic and sexual experiences, this finding is relevant for educators, parents and, in particular, for adolescent women themselves. Although additional research is needed to examine the roles of different SEM genres and the developmental patterns of hyperfemininity and sexual agency in adolescent and young women, further efforts aimed at increasing media literacy and comprehensive sexuality education are needed in raising awareness about unrealistic and stereotypical depictions of sexual interaction and gender relations in SEM (Albury, 2014; Vandenbosch \& van Oosten, 2017). Comprehensive sexual education programs that include discussions about SEM would help young people to develop a healthy and personally fulfilling approach to sexuality and close relationships. 
SEM, HYPERFEMININITY, AND SEXUAL AGENCY

\section{References}

Abrams, K. (1995). Sex wars redux: Agency and coercion in feminist legal theory. Columbia Law Review, 95, 304-376.

Albury, K. (2014). Porn and sex education, porn as sex education. Porn Studies, 1, 172-181. doi:10.1080/23268743.2013.863654

Alexander, M. G., \& Fisher, T. D. (2003). Truth and consequences: Using the bogus pipeline to examine sex differences in self-reported sexuality. Journal of Sex Research, 40, $27-$ 35. doi:10.1080/00224490309552164

Anderson, R. M. (2013). Positive sexuality and its impact on overall wellbeing. Bundesgesundheitsblatt - Gesundheitsforschung - Gesundheitsschutz, 56, 208-214. doi:10.1007/s00103-012-1607-z

Ashton, S., McDonald, K., \& Kirkman, M. (2018). Women's experiences of pornography: A systematic review of research using qualitative methods. The Journal of Sex Research, 55(3), 334-347.

Attwood, F. (2004). Pornography and objectification. Feminist Media Studies, 4; 7-19. doi: $10.1080 / 14680770410001674617$

Bem, S. L. (1981). Gender schema theory: A cognitive account of sex typing. Psychological Review, 88, 354-364. doi:10.1037/0033-295X.88.4.354

Bridges, A. J., Wosnitzer, R., Scharrer, E., Sun, C., \& Liberman, R. (2010). Aggression and Sexual Behavior in Best-Selling Pornography Videos: A Content Analysis Update. Violence Against Women, 16, 1065-1085. doi:10.1177/1077801210382866

Brown, J., \& L'Engle, K. (2009). X-rated: Sexual attitudes and behaviors associated with US 
SEM, HYPERFEMININITY, AND SEXUAL AGENCY

early adolescents' exposure to sexually explicit media. Communication Research, 36, 129-151. doi: 10.1177/0093650208326465

Byrne, B. M. (2010). Structural Equation Modeling with AMOS . (2nd ed.). New York: Routledge.

Calogero, R. M., \& Thompson, J. K. (2009). Potential implications of the objectification of women's bodies for women's sexual satisfaction. Body image, 6(2), 145-148.

Chadwick, S. B., Raisanen, J. C., Goldey, K. L., \& van Anders, S. (2018). Strategizing to Make Pornography Worthwhile: A Qualitative Exploration of Women's Agentic Engagement with Sexual Media. Archives of Sexual Behavior. doi:10.1007/s10508-0181174-y

Claudat, K., \& Warren, C. S. (2014). Self-objectification, body self-consciousness during sexual activities, and sexual satisfaction in college women. Body Image, 11, 509-515. doi:10.1016/J.BODYIM.2014.07.006

Curran, P. J., Obeidat, K., \& Losardo, D. (2010). Twelve frequently asked questions about growth curve modeling. Journal of Cognitive Development, 11, 121-136. doi:10.1080/15248371003699969.Twelve

Curtin, N., Ward, L. M., Merriwether, A., \& Caruthers, A. (2011). Femininity Ideology and Sexual Health in Young Women: A focus on Sexual Knowledge, Embodiment, and Agency. International Journal of Sexual Health, 23, 48-62. doi:10.1080/19317611.2010.524694

de Graaf, H., \& Rademakers, J. (2006). Sexual Development of Prepubertal Children. Journal of Psychology \& Human Sexuality, 18, 1-21. doi:10.1300/J056v18n01_01 
SEM, HYPERFEMININITY, AND SEXUAL AGENCY

Doornwaard, S. M., van den Eijnden, R. J., Overbeek, G., \& ter Bogt, T. F. (2015).

Differential developmental profiles of adolescents using sexually explicit internet material. The Journal of Sex Research, 52(3), 269-281.

Duncan, T., Duncan, S., \& Strycker, L. (2013). An introduction to latent variable growth curve modeling: Concepts, issues, and application. New York: Psychology Press.

Fahs, B., \& McClelland, S. I. (2016). When sex and power collide: An argument for critical sexuality studies. The Journal of Sex Research, 53, 392-416.

Fetterolf, J. C., \& Sanchez, D. T. (2015). The Costs and Benefits of Perceived Sexual Agency for Men and Women. Archives of Sexual Behavior, 44, 961-970. doi:10.1007/s10508014-0408-x

Fine, M., \& McClelland, S. I. (2006). Sexuality Education and Desire: Still Missing after All These Years. Harvard Educational Review, 76, 297-338. doi:10.17763/haer.76.3.w5042g23122n6703

Flora, D. B. (2008). Specifying Piecewise Latent Trajectory Models for Longitudinal Data. Structural Equation Modeling: A Multidisciplinary Journal, 15, 513-533. doi: $10.1080 / 10705510802154349$

Fredrickson, B., \& Roberts, T. (1997). Objectification theory: Toward understanding women's lived experiences and mental health risks. Psychology of Women Quarterly, 21, 173-206. doi: 10.1111/j.1471-6402.1997.tb00108.x

Fritz, N., \& Paul, B. (2017). From Orgasms to Spanking: A Content Analysis of the Agentic and Objectifying Sexual Scripts in Feminist, for Women, and Mainstream Pornography. Sex Roles, 77, 639-652. doi:10.1007/s11199-017-0759-6 
SEM, HYPERFEMININITY, AND SEXUAL AGENCY

Goodson, P., McCormick, D., \& Evans, A. (2001). Searching for Sexually Explicit Materials on the Internet: An Exploratory Study of College Students' Behavior and Attitudes. Archives of Sexual Behavior, 30, 101-118. doi:10.1023/A:1002724116437

Gorman, S., Monk-Turner, E., \& Fish, J. (2010). Free adult Internet web sites: How prevalent are degrading acts? Gender Issues, 27, 131-145. doi: 10.1007/s12147-010-9095-7

Graham, J. W. (2012). Missing Data: Analysis and Design. New York: Springer.

Hare, K. A., Gahagan, J., Jackson, L., \& Steenbeek, A. (2014). Perspectives on “pornography”: Exploring sexually explicit Internet movies' influences on Canadian young adults' holistic sexual health. Canadian Journal of Human Sexuality, 23, 148158. doi:10.3138/cjhs. 2732

Hare, K. A., Gahagan, J., Jackson, L., \& Steenbeek, A. (2015). Revisualising “porn”: How young adults' consumption of sexually explicit Internet movies can inform approaches to Canadian sexual health promotion. Culture, Health, and Sexuality, 17, 269-283. doi:10.1080/13691058.2014.919409

Haste, P. (2013). Sex education and masculinity: the "problem" of boys. Gender and Education, 25, 515-527. doi:10.1080/09540253.2013.789830

Horne, S., \& Zimmer-Gembeck, M. (2006). The female sexual subjectivity inventory: Development and validation of a multidimensional inventory for late adolescents and emerging adults. Psychology of Women Quarterly, 30, 125-138.

Impett, E. A., Schooler, D., \& Tolman, D. L. (2006). To Be Seen and Not Heard: Femininity Ideology and Adolescent Girls' Sexual Health. Archives of Sexual Behavior, 35, 129142. doi:10.1007/s10508-005-9016-0 
SEM, HYPERFEMININITY, AND SEXUAL AGENCY

Johansson, T., \& Hammarén, N. (2007). Hegemonic masculinity and pornography: Young people's attitudes toward and relations to pornography. The Journal of Men's Studies, 15, 57-70. doi: 10.3149/jms. 1501.57

Karsay, K., Knoll, J., \& Matthes, J. (2018). Sexualizing media use and self-objectification: A meta-analysis. Psychology of Women Quarterly, 42, 9-28. doi: $10.1177 / 0361684317743019$

Kiefer, A. K., \& Sanchez, D. T. (2007). Scripting sexual passivity: A gender role perspective. Personal Relationships, 14, 269-290. doi:10.1111/j.1475-6811.2007.00154.x

Klaassen, M. J. E., \& Peter, J. (2015). Gender (In)equality in Internet Pornography: A Content Analysis of Popular Pornographic Internet Videos. The Journal of Sex Research, 52, 721-735. doi:10.1080/00224499.2014.976781

Klein, V., Becker, I., \& Štulhofer, A. (2018). Parenting, communication about sexuality, and the development of adolescent womens' sexual agency: a longitudinal assessment. Journal of youth and adolescence, 47, 1486-1498.

Koletić, G. (2017). Longitudinal associations between the use of sexually explicit material and adolescents' attitudes and behaviors: A narrative review of studies. Journal of Adolescence, 57, 119-133. doi:10.1016/j.adolescence.2017.04.006

Kreager, D. A., Staff, J., Gauthier, R., Lefkowitz, E. S., \& Feinberg, M. E. (2016). The Double Standard at Sexual Debut: Gender, Sexual Behavior and Adolescent Peer Acceptance. Sex Roles, 75, 377-392. doi:10.1007/s11199-016-0618-x

Kreiger, T. C., \& Dumka, L. E. (2006). The Relationships Between Hypergender, Gender, and Psychological Adjustment. Sex Roles, 54, 777-785. doi:10.1007/s11199-006-90449 
SEM, HYPERFEMININITY, AND SEXUAL AGENCY

Lerum, K., \& Dworkin, S. L. (2009). "Bad Girls Rule”: An Interdisciplinary Feminist Commentary on the Report of the APA Task Force on the Sexualization of Girls. Journal of Sex Research, 46, 250-263. doi:10.1080/00224490903079542

Liss, M., Erchull, M. J., \& Ramsey, L. R. (2011). Empowering or Oppressing? Development and Exploration of the Enjoyment of Sexualization Scale. Personality and Social Psychology Bulletin, 37, 55-68. doi:10.1177/0146167210386119

Little, T. D. (2013). Longitudinal Structural Equation Modeling. New York: Guilford Press.

Löfgren-Mårtenson, L., \& Månsson, S.-A. (2010). Lust, Love, and Life: A Qualitative Study of Swedish Adolescents' Perceptions and Experiences with Pornography. Journal of Sex Research, 47, 568-579. doi:10.1080/00224490903151374

Lyons, H., Giordano, P. C., Manning, W. D., \& Longmore, M. A. (2011). Identity, Peer Relationships, and Adolescent Girls' Sexual Behavior: An Exploration of the Contemporary Double Standard. Journal of Sex Research, 48, 437-449. doi:10.1080/00224499.2010.506679

Maas, M. K., Bray, B. C., \& Noll, J. G. (2019). Online sexual experiences predict subsequent sexual health and victimization outcomes among female adolescents: a latent class analysis. Journal of youth and adolescence, 1-13.

Maas, M. K., \& Dewey, S. (2018). Internet pornography use among collegiate women: gender attitudes, body monitoring, and sexual behavior. Sage open, 8(2), 2158244018786640.

McKelvie, M., \& Gold, S. R. (1994). Hyperfemininity: Further definition of the construct. The Journal of Sex Research, 31, 219-228. doi:10.1080/00224499409551755 
SEM, HYPERFEMININITY, AND SEXUAL AGENCY

Moradi, B., \& Huang, Y.-P. (2008). Objectification theory and psychology of women: A decade of advances and future directions. Psychology of Women Quarterly, 32(4), 377398. https://doi.org/10.1111/j.1471-6402.2008.00452.x

Murnen, S. K., \& Byrne, D. (1991). Hyperfemininity: Measurement and initial validation of the construct. Journal of Sex Research, 28, 479-489. doi:10.1080/00224499109551620

Muthén, B. O., \& Curran, P. J. (1997). General longitudinal modeling of individual differences in experimental designs: A latent variable framework for analysis and power estimation. Psychological Methods, 2, 371-402. doi:10.1037/1082-989X.2.4.371

Nowatzki, J., \& Morry, M. M. (2009). Women's Intentions Regarding, and Acceptance of, Self-Sexualizing Behavior. Psychology of Women Quarterly, 33, 95-107. doi:10.1111/j.1471-6402.2008.01477.x

Owens, E., Behun, R., \& Manning, J. (2012). The impact of Internet pornography on adolescents: A review of the research. Sexual Addiction \& Compulsivity, 19, 99-122.

Parvez, Z. F. (2006). The Labor of Pleasure. Gender \& Society, 20, 605-631. doi:10.1177/0891243206291109

Paul, B., \& Shim, J. W. (2008). Gender, Sexual Affect, and Motivations for Internet Pornography Use. International Journal of Sexual Health, 20, 187-199. doi:10.1080/19317610802240154

Peter, J., \& Valkenburg, P. M. (2007). Adolescents' Exposure to a Sexualized Media Environment and Their Notions of Women as Sex Objects. Sex Roles, 56, 381-395. doi:10.1007/s11199-006-9176-y

Peter, J., \& Valkenburg, P. M. (2009). Adolescents’ Exposure to Sexually Explicit Internet Material and Notions of Women as Sex Objects: Assessing Causality and Underlying 
SEM, HYPERFEMININITY, AND SEXUAL AGENCY

Processes. Journal of Communication, 59, 407-433. doi:10.1111/j.1460-

2466.2009.01422.x

Peter, J., \& Valkenburg, P. M. (2011). The Influence of Sexually Explicit Internet Material and Peers on Stereotypical Beliefs About Women's Sexual Roles: Similarities and Differences Between Adolescents and Adults. Cyberpsychology, Behavior, and Social Networking, 14, 511-517. doi:10.1089/cyber.2010.0189

Peter, J., \& Valkenburg, P. M. (2016). Adolescents and Pornography: A Review of 20 Years of Research. The Journal of Sex Research, 53, 509-531. doi:10.1080/00224499.2016.1143441

Petersen, J. L., \& Hyde, J. S. (2011). Gender differences in sexual attitudes and behaviors: A review of meta-analytic results and large datasets. Journal of Sex Research, 48(2-3), $149-165$.

Peterson, Z. D. (2010). What Is Sexual Empowerment? A Multidimensional and ProcessOriented Approach to Adolescent Girls' Sexual Empowerment. Sex Roles, 62, 307-313. doi:10.1007/s11199-009-9725-2

Preacher, K., Wichman, A., MacCallum, R., \& Briggs, N. (2008). Latent Growth Curve Modeling. Thousand Oaks California, CA: SAGE . doi:10.4135/9781412984737

Ramsey, L. R., \& Hoyt, T. (2015). The object of desire: How being objectified creates sexual pressure for women in heterosexual relationships. Psychology of Women Quarterly, 39, 151-170.

Rothman, E. F., Adhia, A., Christensen, T. T., Paruk, J., Alder, J., \& Daley, N. (2018). A Pornography Literacy Class for Youth: Results of a Feasibility and Efficacy Pilot Study. American Journal of Sexuality Education, 13, 1-17. doi: 
SEM, HYPERFEMININITY, AND SEXUAL AGENCY

$10.1080 / 15546128.2018 .1437100$

Sanchez, D. T., Fetterolf, J. C., \& Rudman, L. A. (2012). Eroticizing Inequality in the United States: The Consequences and Determinants of Traditional Gender Role Adherence in Intimate Relationships. Journal of Sex Research, 49, 168-183. doi:10.1080/00224499.2011.653699

Sanchez, D. T., Kiefer, A. K., \& Ybarra, O. (2006). Sexual Submissiveness in Women: Costs for Sexual Autonomy and Arousal. Personality and Social Psychology Bulletin, 32, 512-524. doi:10.1177/0146167205282154

Smith, C., \& Attwood, F. (2014). Anti/pro/critical porn studies. Porn Studies, 1, 7-23. doi:10.1080/23268743.2014.887364

Štulhofer, A., Tafro, A., \& Kohut, T. (2019). The dynamics of adolescents' pornography use and psychological well-being: a six-wave latent growth and latent class modeling approach. European child \& adolescent psychiatry, 1-13.

To, S., Ngai, S. S., \& Iu Kan, S. (2012). Direct and mediating effects of accessing sexually explicit online materials on Hong Kong adolescents' attitude, knowledge, and behavior relating to sex. Children and Youth Services Review, 34, 2156-2163. doi:10.1016/j.childyouth.2012.07.019

Tolman, D. L. (2005). Dilemmas of desire : teenage girls talk about sexuality. Cambridge, MA: Harvard University Press.

Tolman, D. L., Impett, E. A., Tracy, A. J., \& Michael, A. (2006). Looking Good, Sounding Good: Femininity Ideology and Adolescent Girls' Mental Health. Psychology of Women Quarterly, 30, 85-95. doi:10.1111/j.1471-6402.2006.00265.x 
SEM, HYPERFEMININITY, AND SEXUAL AGENCY

van de Bongardt, D., Yu, R., Deković, M., \& Meeus, W. H. J. (2015). Romantic relationships and sexuality in adolescence and young adulthood: The role of parents, peers, and partners. European Journal of Developmental Psychology, 12, 497-515. doi:10.1080/17405629.2015.1068689

van Oosten, J. M. F., Peter, J., \& Boot, I. (2015). Women's Critical Responses to Sexually Explicit Material: The Role of Hyperfemininity and Processing Style. The Journal of Sex Research, 52, 306-316. doi:10.1080/00224499.2013.858305

van Oosten, J. M. F., Vandenbosch, L., \& Peter, J. (2017). Gender roles on social networking sites: investigating reciprocal relationships between Dutch adolescents' hypermasculinity and hyperfemininity and sexy online self-presentations. Journal of Children and Media, 11, 147-166. doi:10.1080/17482798.2017.1304970

Vandenbosch. (2015). Antecedents of adolescents' exposure to different types of sexually explicit Internet material: A longitudinal study. Computers in Human Behavior, 50, 439-448. doi:10.1016/j.chb.2015.04.032

Vandenbosch, L., \& van Oosten, J. M. F. (2017). The Relationship Between Online Pornography and the Sexual Objectification of Women: The Attenuating Role of Porn Literacy Education. Journal of Communication, 67, 1015-1036. doi:10.1111/jcom.12341

Vandenbosch, \& Peter. (2016). Antecedents of the Initiation of Watching Sexually Explicit Internet Material: A Longitudinal Study Among Adolescents. Mass Communication and Society, 19, 499-521. doi:10.1080/15205436.2016.1148171

Wallmyr, G., \& Welin, C. (2006). Young people, pornography, and sexuality: sources and attitudes. The Journal of School Nursing, 22, 290-295. doi: 
SEM, HYPERFEMININITY, AND SEXUAL AGENCY

$10.1177 / 10598405060220050801$

Ward, L. M. (2016). Media and Sexualization: State of Empirical Research, 1995-2015. The Journal of Sex Research, 53, 560-577. doi:10.1080/00224499.2016.1142496

Ward, L. M., Seabrook, R. C., Grower, P., Giaccardi, S., \& Lippman, J. R. (2018). Sexual Object or Sexual Subject? Media Use, Self-Sexualization, and Sexual Agency Among Undergraduate Women. Psychology of Women Quarterly, 42, 29-43. doi: $10.1177 / 0361684317737940$

Weinberg, M. S., Williams, C. J., Kleiner, S., \& Irizarry, Y. (2010). Pornography, Normalization, and Empowerment. Archives of Sexual Behavior, 39, 1389-1401. doi:10.1007/s10508-009-9592-5

Wilkins, A. S. (2018). To Lag or Not to Lag?: Re-Evaluating the Use of Lagged Dependent Variables in Regression Analysis. Political Science Research and Methods, 6, 393-411. doi:10.1017/psrm.2017.4

Young, M., Cardenas, S., Donnelly, J., \& J. Kittleson, M. (2016). Perceptions of Peer Sexual Behavior: Do Adolescents Believe in a Sexual Double Standard? Journal of School Health, 86, 855-863. doi:10.1111/josh.12455

Zimmer-Gembeck, M. J., \& French, J. (2016). Associations of Sexual Subjectivity with Global and Sexual Well-Being: A New Measure for Young Males and Comparison to Females. Archives of Sexual Behavior, 45, 315-327. doi:10.1007/s10508-014-0387-y

Zurbriggen, E. L., Collins, R. L., Lamb, S., Roberts, T.-A., Tolman, D. L., Ward, E. L. M., \& Blake, J. (2010). Report of the APA Task Force on the Sexualization of Girls APA Task Force on the Sexualization of Girls Members. American Psychological Association. Retrieved from www.apa:pi/women/programs/girls/report-full.pdf 
SEM, HYPERFEMININITY, AND SEXUAL AGENCY

Table 1 - Bivariate Correlations and Statistical Descriptors of Key Variables

\begin{tabular}{|c|c|c|c|c|c|c|c|c|c|c|c|}
\hline & 1 & 2 & 3 & 4 & 5 & 6 & 7 & 8 & $\mathrm{M}$ & $\mathrm{SD}$ & Range \\
\hline 1 SEM use at T1 & - & $.67 * *$ & $.56^{* *}$ & $.58 * *$ & $.57 * *$ & $.17^{* *}$ & $.10^{*}$ & .00 & 1.78 & 1.40 & $1-8$ \\
\hline 2 SEM use at $\mathrm{T} 2$ & & - & $.70^{* *}$ & $.71 * *$ & $.65^{* *}$ & $.20^{* *}$ & .08 & .01 & 1.84 & 1.41 & $1-8$ \\
\hline 3 SEM use at T3 & & & - & $.71 * *$ & $.67^{* *}$ & $.15^{* *}$ & $.12 *$ & -.05 & 1.85 & 1.48 & $1-8$ \\
\hline 4 SEM use at T4 & & & & - & $.77 * *$ & $.20^{* *}$ & .09 & -.02 & 1.95 & 1.54 & $1-8$ \\
\hline 5 SEM use at T5 & & & & & - & $.16^{* *}$ & $.17 * *$ & $-.10^{*}$ & 1.92 & 1.49 & $1-8$ \\
\hline 6 Sexual agency (T5) & & & & & & - & $.16^{* *}$ & $.32 * *$ & 11.71 & 2.66 & 3-15 \\
\hline 7 Hyperfemininity (T5) & & & & & & & - & $-.14 * *$ & 15.32 & 4.75 & $6-30$ \\
\hline 8 Sexual satisfaction (T5) & & & & & & & & - & 5.23 & 1.60 & $1-7$ \\
\hline
\end{tabular}

$* \mathrm{p}<.05, * * \mathrm{p}<.01$ 
SEM, HYPERFEMININITY, AND SEXUAL AGENCY

Table 2 - Correlates of Sexual Agency and Hyperfemininity in Adolescent Croatian Women

\begin{tabular}{|c|c|c|}
\hline & $\begin{array}{c}\text { Sexual agency } \\
(n=435)\end{array}$ & $\begin{array}{l}\text { Hyperfemininity } \\
\qquad(n=415)\end{array}$ \\
\hline & $b(\mathrm{SE})$ & $b(\mathrm{SE})$ \\
\hline Sexual satisfaction & $0.55(.07)^{* *}$ & $-0.29(.15)$ \\
\hline Father's education & $0.14(.22)$ & $-0.10(.47)$ \\
\hline Mother's education & $0.08(.21)$ & $0.44(.45)$ \\
\hline Religiosity & $-0.25(.08)^{*}$ & $-0.21(.17)$ \\
\hline Intercept $t^{\mathrm{a}}$ & $11.70(.13)$ & $15.30(.24)$ \\
\hline $\mathrm{ICC}^{\mathrm{a}, \mathrm{b}}(\%$ of data nestedness in schools) & .03 & .03 \\
\hline
\end{tabular}


SEM, HYPERFEMININITY, AND SEXUAL AGENCY

Figure 1 - Latent Growth in the Use of Sexually Explicit Material as Predictor of Female Sexual Agency and Hyperfemininity $(\mathrm{n}=552)$

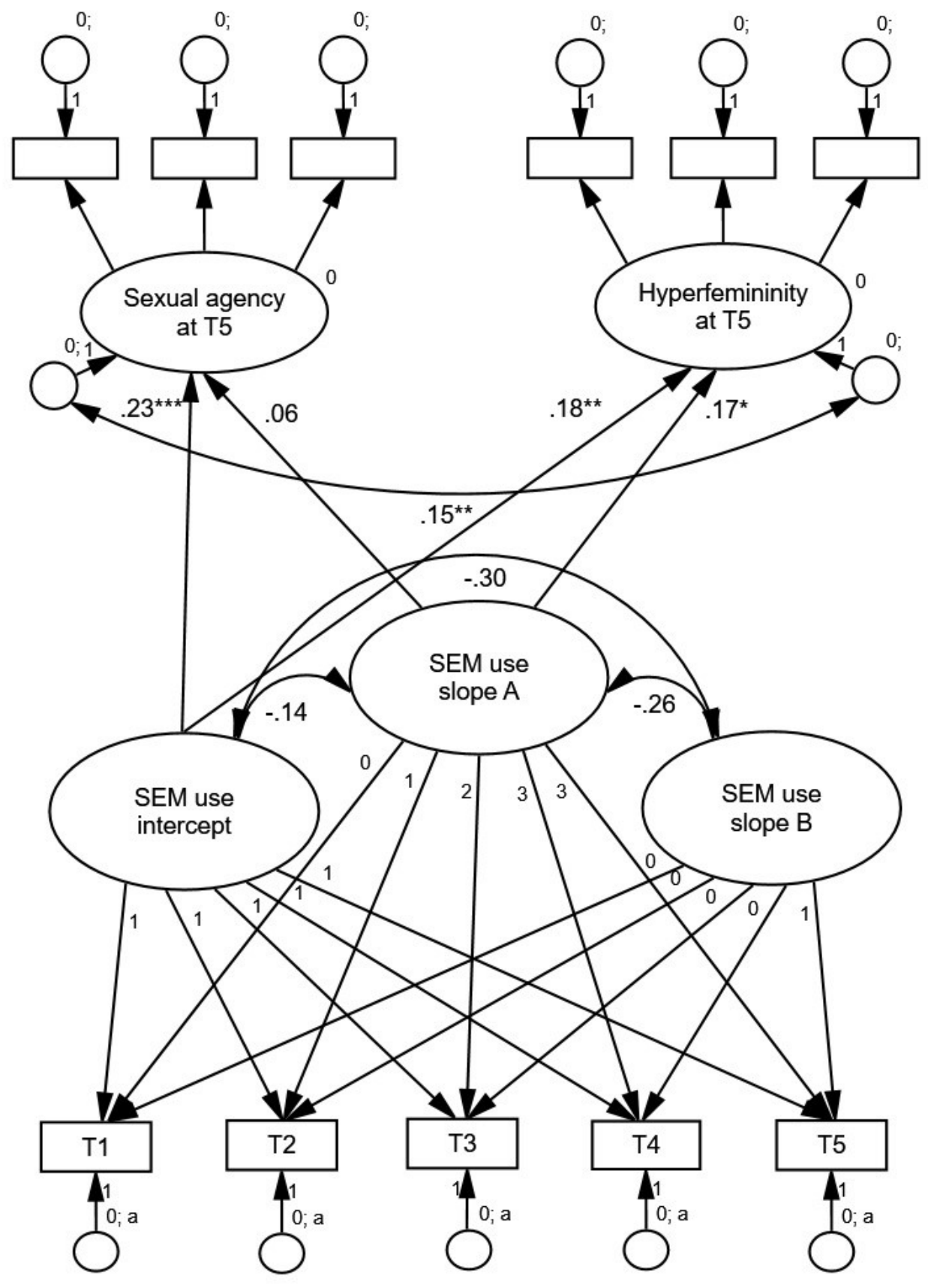

Notes. Model fit: $\chi^{2}{ }_{(44)}=91.40, \mathrm{TLI}=.98, \mathrm{CFI}=.98, \mathrm{RMSEA}=.044(90 \% \mathrm{CI}=.031-.057)$ $* p<.05, * * p<.01, * * * p<.001$ 